\title{
LA PROBLEMÁTICA DEL BAUTISMO DEL SER DEFORME (MONSTRUO) DURANTE LA EDAD MODERNA
}

\author{
POR \\ Ma ALEJANDRA FLORES DE LA FLOR \\ Universidad de Cádiz
}

\section{RESUMEN}

El bautismo ha sido siempre uno de los más importantes sacramentos de la Santa Iglesia Católica. Su administración lo componían una serie de rituales complejos en los que había tener presente diferentes elementos, entre ellos el alma, considerada el elemento principal que permitía el acceso al bautismo, sin ella ningún ser podía ser bautizado. El nacimiento de los seres deformes (considerados monstruos) generó, por tanto, una problemática que obligó a los clérigos, en sus manuales de confesores, a reflexionar sobre sus almas y su derecho al bautismo.

\section{PALABRAS CLAVE}

Monstruo; bautismo; alma; manuales de confesores.

\section{THE PROBLEM OF THE BAPTISM IN DEFORMED BEINGS (MONSTERS) DURING THE EARLY MODERN AGE}

\section{ABSTRACT}

Baptism has always been one of the most important sacraments of the Holy Catholic Church. The administration was made up of a series of complex rituals in which it had to keep in mind various factors, including the soul, considered the main element allowing access to baptism, without it any being could be baptized. The birth of deformed beings (considered monsters) generated, therefore, a problem that forced the 
clergy, in their confessors manuals, to reflect on their souls and their right to be baptized.

KEY WORDS

Monsters; baptism; soul; confessors manuals.

$\begin{array}{ll}\text { Recibido/Received } & 20-12-2012 \\ \text { Aceptado/Accepted } & 13-03-2014\end{array}$

\section{INTRODUCCIÓN}

No resulta fácil definir al ente monstruoso en el contexto de la Edad Moderna, periodo en el que según Elena del Rio Parra se produjo un verdadero "boom" teratológico ${ }^{1}$ que afectó a diversos campos del conocimiento humano, a saber, la medicina, la teología, la jurisdicción, e incluso la propia literatura. ${ }^{2}$ La dificultad a la hora de definir "monstruo" en este periodo histórico radica en la amplitud del concepto en sí mismo, ${ }^{3}$ que implícitamente hizo que en su definición se incluyera desde naciones caracterizadas por un defecto, por ejemplo, cinocéfalos, acéfalos o esciápodos, etc. hasta personas con deformidades físicas más o menos graves -desde un lunar más grande de lo normal hasta seres bicípites-. Consecuentemente, este hecho convirtió al monstruo en un saco, un batiburrillo, en que se incluía todo lo que se salía de lo normal, ${ }^{4}$ situándolo en los márgenes de la naturaleza, no porque no formara parte

${ }^{1}$ Del Río Parra, Elena. 2003. Una era de monstruos: representaciones de lo deforme en el Siglo de Oro español: 29-30, Madrid: ed. Iberoamericana.

2 Como muy bien explica esta autora, determinados fenómenos tales como los monstruos exigían ser tenidos en cuenta desde diferentes ángulos, siendo imprescindible el diálogo entre los discursos científico, político y filosófico, a los que necesariamente había que sumar el literario y el iconográfico. Lo monstruoso era, de ese modo, lo que no se podía representar sino de forma aproximada y desde varios flancos. Ibidem, 18.

${ }^{3}$ Esta amplitud aún puede observarse en el Diccionario de la Real Academia Española cuya definición de "monstruo" recoge siete acepciones, abarcando desde producciones contra el orden regular de la naturaleza hasta una expresión más coloquial que hace referencia a personas con cualidades extraordinarias.

${ }^{4}$ "Son monstruos los que no se ajustan a patrones establecidos». Lafuente, Antonio; Valverde, Nuria. 2000. "¿Qué se puede hacer con los monstruos?" en VV.AA.: Monstruos y seres imaginarios en la Biblioteca Nacional: 11, Madrid: Algete, 
de ella, sino porque aún siendo hecho de la misma materia que el resto de los seres vivos que se encontraban en ella, variaba de manera degenerativa su forma natural. ${ }^{5}$

Esta dificultad a la hora de definir al "monstruo", que se hereda de la Edad Media y el Renacimiento a raíz de los libros de viajes que consideraban monstruoso todo lo que era inusual, ${ }^{6}$ es algo que se observa de manera clara en las obras teratológicas, especialmente por los múltiples intentos de definición que en ellas se recogían. Un ejemplo lo encontramos en el tratado del médico y cirujano zaragozano José Rivilla Bonet y Pueyo, Desvíos de la Naturaleza o Tratado del origen de los monstruos (1695), ${ }^{7}$ pues sus dos primeros capítulos están dedicados a reflexionar sobre la noción misma de la palabra "monstruo". Si bien el primero supone una explicación de lo que implicaba el ser monstruoso, ya sea como algo "que excede los límites de lo común» o como señal de algún «sucesso futuro»; el segundo no es más que un intento por concretar el término en sí mismo, que concluye ofreciendo una explicación extensa de su propia definición: «El monstruo es todo aquel compuesto animado, en cuya producción no espontanea falta mas o menos enormemente à su acostumbrado orden la Naturaleza». ${ }^{8}$ Asimismo, los diccionarios de la época, tales como Tesoro de la lengua castellana de Covarrubias, no dejaron de resaltar ese desvío de lo natural implícito en la monstruosidad:

«Monstro [sic]: Es cualquier parto contra la regla y orden natural, como nacer el hombre con dos cabeças, quatro brazos y quatro piernas; como aconteció en el condado de Urgel, en un lugar dicho Cerbera, año 1343, que nació un niño con dos cabeças y quatro pies; los padres y los demás que estaban presentes a su nacimiento, pensando supersticiosamente pronosticar algún mal y

5 Tanto Luis de Mercado como Pedro García Carrero, siguiendo a Aristóteles, consideraban que el ser monstruoso estaba a los márgenes de la naturaleza, aunque no por eso fuera de ella. El monstruo formaba parte de la misma pero de una manera degenerativa. Cfr. Mercado, Luis. 1594. De Mulierum affectionibus, Libri quatuor: 390, Madrid: Apud Thomam luntam; García Carrero, Pedro. 1605. Disputationes medicae: 1182b, Madrid: ex Officina lusti Sanchez Crespo.

${ }^{6}$ Cfr. Wilson, Dudley. 1993. Signs and portents. Monstruous birth from the Middle Ages to the Englightenment: 12, Londres/Nueva York: Routedge.

${ }^{7}$ Desvíos de la Naturaleza o Tratado del origen de los monstruos, es la primera obra escrita en español dedicada exclusivamente al estudio de los monstruos, siendo la contribución más importante de la literatura médica del siglo XVII al conocimiento de las anomalías congénitas.

${ }^{8}$ Rivilla Bonet y Pueyo, José. 1695. Desvíos de la naturaleza o tratado del origen de los monstruos: Cap. II Fol. 11, Lima: Imprenta Real. 
que con su muerte se evitaría, le enterraron vivo. Sus padres fueron castigados como parricidas, y los demás con ellos [...]». ${ }^{9}$

No obstante, la problemática en torno al ser monstruoso en la Edad Moderna no sólo radicó en su propia definición, sino que fueron muchos los interrogantes que suscitaron, ya fuera desde un punto de vista biológico, filosófico, jurídico o religioso, siendo éste último el centro del presente trabajo. A su vez, la cuestión religiosa se subdivide en dos problemas que son complementarios: el debate sobre la cualidad y la localización de las almas en los seres monstruosos y, consecuentemente, la posterior administración del sagrado sacramento del bautismo. Estas dos cuestiones estaban presentes en todas aquellas obras en que se hacían referencia, en mayor o menos medida, a los monstruos ya fuera un tratado médico, ya una obra de carácter filosófico o religioso. Lo que pone de manifiesto una preocupación muy extendida entre los distintos autores, por lo que implicaba para el ser humano el estar o no bautizado, sobre todo en la Edad Moderna, periodo en el que la religión abarcó todo los recovecos de la vida del hombre. Es por esto que las fuentes utilizadas en este trabajo son muy numerosas y diversas. En primer lugar, están las obras que se incluyen dentro de lo que llamamos filosofía natural, tales como la de Eusebio Nieremberg, Curiosa y oculta filosofía (1649), ${ }^{10}$ o Antonio de Fuentelapeña, El ente dilucidado (1677), que representan el modelo de conocimiento propio del Barroco caracterizado por lo que se ha llamado la visión emblemática del mundo, ${ }^{11}$ en la que los monstruos eran considerados seres que podían encontrarse en la naturaleza y que, por tanto, debían ser incluidos y analizados; obras de carácter médico como la ya citada de José Rivilla Bonet y Pueyo, la de Antonio José Rodríguez, Nuevo aspecto de theología médico-moral, y ambos derechos, o paradoxas physicotheologico legales (1763), la de Lorenzo de Hervás y Panduro, Historia de la vida del hombre (1789), o la de Joseph Jacob Von Plenck, Medicina y cirugía forense ó legal (1796), en las que el monstruo estaba envuelto en un halo de cientifismo, aparente muchas veces, y en que los avances en el campo de la Medicina se alternaban con elementos extraídos de la literatura de maravillas; y por último, los fundamentales manuales de confesores, $^{12}$ tales como Suma de la theologia moral (1702) de Jaime

9 Covarrubias, Sebastián. 1977. Tesoro de la lengua castellana: 812, Madrid: ed. Turner.

${ }^{10}$ Cfr. Marcaida López, José Ramón. 2011. Juan Eusebio Nieremberg y la ciencia del Barroco. Conocimiento y representación de la naturaleza en la España del siglo XVII, Tesis doctoral, Universidad Autónoma de Madrid.

${ }^{11}$ Cfr. Ashworth Jr., William B: "Natural history and the emblematic world view" en Lindberg, David C. y Westman, Robert S. (Eds.) 1990. Reappraisals of the scientific revolution, Cambridge: Cambridge University Press.

12 Los manuales de confesores fue una género literario que floreció a lo largo de los siglos XVI y XVII cuyo objetivo era el de prestar ayuda a los 
Corella o Suma moral para examen de curas y confesores (1770) de Luis Vicente Mas.

El contexto histórico en el que se encuadra nuestro trabajo puede resultar, a primera vista, muy amplio al abarcar todo el periodo moderno. La razón de esto se debe, principalmente, a que en todo este tiempo parece no haber cambios significativos en lo que respecta a la cuestión del bautismo de los monstruos, tal y como podremos comprobar a través de las explicaciones dadas por los diferentes autores. Por este hecho consideramos plausible un análisis en bloque de este tema para toda la Edad Moderna, con el fin de dar una visión general de la problemática del bautismo en los casos de monstruosidad.

\section{EL ALMA Y EL BAUTISMO}

El bautismo era, y es, uno de los sacramentos más importantes de la religión católica. Su importancia para el periodo moderno puede apreciarse en la breve definición que Jaime Corella ofrecía de dicho término en su obra Suma de la theología moral (1702): «El sacramento del Bautismo es uno de los siete de la Católica Iglesia, el primero, y como fundamento de los demás, la puerta por donde entramos en la Iglesia, y con que nos diferenciamos los Christianos de los Infieles». ${ }^{13} \mathrm{El}$ bautismo, tal y como señala Corella, era una puerta de entrada que permitía no sólo acceder a la verdadera religión, sino también a una distinción con respecto a los infieles. Gracias a él, el nuevo cristiano quedaba liberado del pecado original -que afectaba a la humanidad desde los tiempos de Adán y Eva- y garantizaba el acceso a la salvación eterna, siempre y cuando viviera de manera acorde a los preceptos de la fe católica. La importancia de este sacramento, además, iba más allá de lo meramente religioso, ya que ser bautizado suponía el acceso a una comunidad

sacerdotes con cura de almas, poniendo en sus manos los conocimientos más imprescindibles para el conveniente desempeño de su ministerio, sumas que no contenían más que soluciones de casos concretos, sin abordar los problemas fundamentales de la moral. Morgado García, Arturo: "Discursos eclesiásticos en la España de Felipe V", en Pereira Iglesias, J. L. (Ed.). 2002. Felipe $V$ de Borbón 1701-1746: actas del Congreso de San Fernando (Cádiz) de 27 de noviembre a 1 de diciembre de 2000, Córdoba: Ed. Universidad de Córdoba y Fundación Municipal de San Fernando. pp. 435-466. Junto con los trabajos de Arturo Morgado García, especialista en manuales de confesores, recientemente encontramos los trabajos de Antonio González Polvillo entre los que cabe destacar: González Polvillo, Antonio. 2010. Análisis y repertorio de los tratados y manuales para la confesión en el mundo hispánico (ss. XV-XVIII), Huelva, Servicio de Publicaciones de la Universidad de Huelva.

${ }^{13}$ Corella, Jaime. 1702. Suma de la theologia moral: Conferencia I, 216 Barcelona: Imprenta de de Joseph Llopis. 
religiosa dominante en la sociedad española moderna. No estar bautizado, en este contexto, implicaba una marginalidad total y un rechazo para el individuo, quien no recibía nombre cristiano ni era formalmente reconocido por sus padres, pudiendo ser desposeído de sus bienes y privado de sus derechos civiles. ${ }^{14}$

El alma jugó un papel esencial en el sacramento del bautismo. En los casos de monstruosidad fueron dos los elementos a tener en cuenta: cuantía de las almas en los seres bicorpóreos y bicípites, ${ }^{15}$ que generó el debate de la localización anatómica de las mismas; y la racionalidad de éstas en los seres híbridos, es decir, en los monstruos frutos del bestialismo (unión sexual entre humanos -hombre o mujer- y animal, ver llustración 1). ${ }^{16}$ El hecho de que los autores se dedicaran a reflexionar sobre estos dos aspectos se debió a que hubo un interés por parte de la Iglesia en admitir a los monstruos dentro de la comunidad religiosa. En este sentido, hay que tener presente que la Iglesia Católica, además de ser la única religión oficial en la España de la Edad Moderna, era -y en parte sigue siéndolo- una institución religiosa que buscaba la salvación de las almas de los individuos que formaban parte de ella, y con ese fin llevó a cabo una misión evangelizadora para incrementar el número de fieles. Ésta sirvió de justificación a los dirigentes eclesiásticos para aceptar la admisión de los monstruos en la comunidad católica, con la idea de que éstos resucitarían sin deformidades el día del juicio como así señalaba Antonio de Fuentelapeña: «Los tales han de resucitar el dia del juicio, sin aquella deformidad [...] porque la resurrecion es obra de solo Dios, que las obras de Dios deben ser perfectas». ${ }^{17}$ Esta excusa se

14 Salamanca Ballesteros, Alberto. 2007. Monstruos, ostentos y hermafroditas: 89, Granada: ed. Universidad de Granada.

15 Resulta conveniente explicar aquí la diferencia que nosotros entendemos por monstruo bicípite y monstruo bicorpóreo. Tanto uno como otro forman parte de lo que hoy se denomina siameses, es decir, gemelos cuyos cuerpos permanecen unidos después del nacimiento. Sin embargo, mientras que en el segundo hay una conexión superficial en la que ambos individuos están bien desarrollados y son biológicamente independientes, en el primero la conexión es más profunda ya que, en ocasiones, se comparten órganos vitales llegándose al extremo de que uno de los hermanos solo sea un huésped en el cuerpo del otro hermano.

16 Sobre los monstruos híbridos recomendamos un trabajo anterior: Flores de la Flor, Ma Alejandra. 2011. "Los monstruos híbridos en la Edad Moderna", en Morgado García, Arturo; Rodríguez Moreno, José Joaquín (Coord.): Los animales en la historia y en la cultura: 143-152, Cádiz: Servicio de Publicaciones de la Universidad de Cádiz.

${ }^{17}$ Fuentelapeña, Fray Antonio de. 1676. El ente dilucidado. Discurso único novísimo que muestra hay en naturaleza animales irracionales invisibles y quales sean: Sección 2. Duda 2. Fol. 30, Madrid: Imprenta real. Ya otros autores europeos insistían en la perfección del cuerpo humano tras la 
explica porque la Iglesia entendía por monstruoso al ser que estaba deforme físicamente, es decir, que la monstruosidad afectaba al cuerpo pero no al alma racional, ${ }^{18}$ pues en ésta no podía «aver falta, no excesso (aunque puede aver mas o menos repleción) no otra monstruosidad, que la espiritual del pecado». ${ }^{19}$ Toda esta teoría, basada en la perfección inmortal del alma, convirtió a los monstruos en seres iguales al resto de los humanos -al menos en un plano espiritual- $y$, por tanto, con pleno derecho a la salvación a la que se accedía a través de los sacramentos administrados por la Santa Iglesia Católica. ${ }^{20}$

Es por eso que, al igual que los juristas razonaron acerca del status legal y social de los monstruos, los clérigos se ocuparon de discernir la presencia del alma en los recién nacidos y si eran "capaces de bautismo". De ahí que los tratadistas, muchos de origen eclesiástico, dedicasen amplios espacios de sus obras a reflexionar sobre las almas y el bautismo. Y si bien es cierto que en la Edad Moderna se produjo un "boom" en cuanto a lo que teratología se refiere, ya en la Edad Media pueden encontrarse indicios del mencionado debate, especialmente dado entre dos grupos: los juristas civiles y los canonistas. Los primeros se centraron específicamente en clasificar al monstruo según su apariencia, pues la situación jurídica de éste, sobre todo en relación con la herencia o responsabilidad jurídica, era analizada desde el punto de vista de la forma. Los segundos, no obstante, se preocuparon más por el alma del monstruo, sobre todo a raíz de la problemática surgida entre los párrocos de pueblos que tenían que decidir si el niño monstruoso podía o no podía recibir bautismo. Esta cuestión, que alcanzó una gran importancia en el setecientos debido al incremento de monstruosidades, impulsó a los teólogos a especular sobre la humanidad del ser deforme plasmando sus conclusiones en lo que se conoce como manuales parroquiales. ${ }^{21}$

resurrección como Ulises Aldrovandi: «Notandum est homines, sublato omni corporis vitio, novissimo die esse resurrecturos». Aldrovandi, Ulises. 1642. Monstrorum historia, cap. 1, 160 Bolonia: Hieronimus Tamburinus.

${ }^{18}$ Martínez Gil explica que la belleza del cuerpo de los bienaventurados era una cuestión importante en la resurrección. Se pensaba que cada cuerpo de los bienaventurados resucitaba con el mismo rostro que tuvo, pero quitados todos los defectos y deformidades, de modo que no habrá ni ciegos, ni cojo, ni tullidos, no hombre muy gordo, ni muy flacos. Martínez Gil, Fernando 2000. Muerte y sociedad en la España de los Austrias: 488, Cuenca: Servicio de Publicaciones de la Universidad de Castilla-La Mancha.

${ }_{19}$ Rivilla Bonet y Pueyo, José. 1695: Cap. II Fol. 11.

${ }^{20}$ Del Rio Parra, Elena. 2003: 101.

${ }^{21}$ Friedman, John Block. 1981. The monstrous races in medieval art and thought: 180, Cambridge (Massachusetts): Harvard University Press. 


\section{LA CUESTIÓN SOBRE LA RACIONALIDAD Y LOCALIZACIÓN DEL ALMA}

Poseer un alma racional era un elemento esencial para acceder al sagrado sacramento del bautismo, ${ }^{22}$ por eso no es extraño que se generase todo un debate en torno al alma del ser monstruoso: ¿Poseía éste alma racional? Obviamente, no todos los tipos de monstruos eran iguales $\mathrm{y}$, en ocasiones, la identificación de ésta como racional podía volverse confusa, principalmente en lo que se refiere a seres híbridos. Sin embargo, una idea era clara, y es que las monstruosidades que nacían de la especie humana -padre y madre humanos- tales como aquellos que nacían con algún tipo de deformidad: labios leporinos, mancos, carentes de alguna pierna, siameses, etc. poseían alma racional y eran, por tanto, aptos al bautismo, como así lo explicaba J. J. Plenk ${ }^{23}$ en Medicina y cirugía forense o legal (1796): "Se pregunta si los monstruos vivos tienen alma. Si son verdaderos hombres [...]. Que los monstruos que nacen de la especie humana tienen alma, lo demuestra el uso de las potencias de esta que se observa de ellos». ${ }^{24}$ Volviendo a insistir en la misma idea posteriormente: "Que los monstruos humanos tienen alma racional, lo enseña la experiencia que hay del uso de las potencias. Por lo tanto se deben bautizar». ${ }^{25}$

No obstante, la racionalidad de las almas se volvía dudosa cuando se trataba de monstruos híbridos (llustración 1). La naturaleza de éstos, es decir, el descender de padre o madre humana y bruto, hacía que los tratadistas se cuestionaran hasta qué punto el alma de estos seres era racional. No todos los autores compartían la misma duda, José Rivilla, por ejemplo, se mostraba muy claro al rechazar la racionalidad de las almas en los monstruos híbridos:

${ }^{22}$ La insistencia en la racionalidad del ser monstruoso es algo que va a estar presente en la cuestión del bautismo durante toda la Edad Moderna y en autores de diversa índole. Así, en disertaciones de la Regia Sociedad de Medicina y otras Ciencias de Sevilla que trataban sobre esta cuestión, insistían en que había que tener presente el tema de la racionalidad. Véase Hermosilla Molina, Antonio. 1970. Cien años de medicina sevillana: 482 Sevilla, Diputación provincial.

23 Joseph Jacob Von Plenck (1738-1807) fue un médico y botánico austríaco, principalmente conocido por ser pionero en el campo de la dermatología al que contribuyó proponiendo una clasificación de las enfermedades cutáneas. Su obra, traducida al español en 1796, tuvo una gran influencia en la medicina español, sobre todo desde una perspectiva legal.

${ }^{24}$ Von Plenk, J. J. 1796. Medicina y cirugía forense ó legal: 138, Madrid: Imprenta de la viuda e hijo de Marín, 1796. Traducida al castellano por Higinio Antonio Lorente.

${ }^{25}$ Ibidem: 151. 
«el anima pide por si misma sola aquella materia, aquellos miembros, y o órganos que tienen disposicion para admitirla por razon de la creacion de su especie; tanto, que aun la materia misma de la simiente humana sino esta suficientemente dispuesta, no la recibe». ${ }^{26}$

Se entiende en este fragmento, por tanto, que para el médico zaragozano el alma requería de un cuerpo humano perfecto para residir y que los monstruos híbridos, al carecer del mismo, no podían poseer un alma totalmente racional. Rivilla no se quedó en esta simple explicación y propuso una solución a este problema y, al igual que teorizó sobre a qué especie pertenecían los seres híbridos situándolos en un género intermedio entre lo animal y lo humano, también estableció una categoría para el alma de los mismos, un alma neutra que se situaba entre lo racional y lo irracional:

«Y aunque resulta de aquí la dificultad de saber, que alma será la que tendrá tal monstruo, no pudiendo ser la racional, por lo que se ha dicho, ni la de Animal que concurrió, por no poder una simiente sola general, ni la de otro alguno, por no poder el alma de uno informase en la simiente del otro se dize, que entonces sacare el Monstruo, una anima material conveniente a aquel mixto». ${ }^{27}$

Para este autor, además de la humanidad del cuerpo, era imprescindible también la humanidad y la racionalidad de los padres, no admitiendo la residencia del alma humana en los seres fruto de la unión de un humano y un animal, aunque éste fuese enteramente humano: «Hombre y bestia, no pueden producir anima racional según la opinión común, no solo quando el parto nace con miembros de ambas especies, sino aun lo que es mas, quando saliese todo con forma humana». ${ }^{28}$

La cuestión sobre los monstruos híbridos se complicó sobremanera en el siglo XVIII cuando los autores proporcionaron diferentes reglas y opiniones. El ya citado Jaime Corella, por ejemplo, explicaba que en los casos de conmixtión de especies, el monstruo debía ser bautizado bajo condición en los casos en los que el padre fuera humano y la madre animal, sin embargo, negaba el bautismo en el caso contrario, es decir, si el padre fuese animal y la madre humana. ${ }^{29}$ Esta idea se entiende, obviamente, por la fuerte importancia que durante siglos tuvo la simiente

${ }^{26}$ Rivilla Bonet y Pueyo, José. 1695: Cap. IV. Fol. 31

${ }^{27}$ Ibidem: Cap. IV. Fol. 31.

28 Ibidem Cap. IV. Fol. 32.

29 «El que es engendrado de bruto, y muger, no es capaz de Bautismos mas sì el que lo es de hombre, y bruta, alomenos podrá bautizarse debajo de condición». Corella, Jaime. 1702: Conferencia 3, 231. 
masculina por encima de la femenina debido a la influencia de la teoría aristotélica de la generación. Según ésta, era imprescindible el semen del hombre para engendrar, siendo el vientre materno únicamente un recipiente donde el ser engendrado se desarrollaba. Parece obvio, por tanto, que si un animal daba a luz a un "ser" producto de la cópula con un hombre, éste fuese mucho más racional que si fuera nacido de madre humana y padre animal, pues la simiente masculina predominaba a la hora de calificar al ser como racional o no. Y es que la teoría aristotélica consideraba al macho de cualquier especie como el único generador del feto, y a la hembra -mujer en la especie humana- la convertía en un invernadero donde se alimentaban a los seres diminutos sembrados en su interior. ${ }^{30}$ De la misma opinión se mostró José F. Cliquet en La flor del moral...(1786): "Si el monstruo tiene origen de hombre, y hembra beluina, se debe bautizar sub conditione, porque probablemente es hombre; pero si es monstruo de mujer, y bruto, no se debe bautizar, pues es cierto que no es hombre el producido sin hombre». ${ }^{31}$ La concepción aristotélica de la generación humana, que tan bien arraigada estaba en los manuales de confesores, desaparecía en obras con un marcado carácter médico, a favor de una postura ovista ${ }^{32}$ en la que la racionalidad ya no se transmitía por la línea paterna sino por la materna, tal y como se verá a continuación con el ejemplo de Antonio José Rodríguez.

Vicente Mas, sin embargo, pareció decantarse por otra opción a la hora de decidir sobre la racionalidad de los monstruos híbridos. Para él, el saber si el fruto de la conmixtión era humano o no, dependía de si éste poseía cabeza humana: "Si el monstruo tiene la cabeza y pecho de hombre, aunque los demás miembros sean de bestia, se juzga ser hombre, y capaz de bautismo. Pero si tuviese la cabeza de bruto, [...]

${ }^{30}$ Salamanca Ballesteros, Alberto. 2007: 238.

${ }^{31}$ Existía la posibilidad de que se dudase por la especie del padre, ante lo cual Cliquet afirmaba que «en duda si proviene de macho bruto, se debera bautizar, si en pecho y cabeza tiene forma de hombre...». Cliquet, Jose Faustino. 1781. La flor del mora o recopilación legal, firme, y opulenta, de lo mas florido, y selecto...: Tomo I. Tratado II Cap. V, 55, Madrid: Por Antonio Sanz.

32 El preformacionismo (también llamado preformismo o teoría preformista) es una antigua teoría biológica según la cual el desarrollo de un embrión no era más que el crecimiento de un organismo que estaba ya preformado (homúnculo). Una de las dos vertientes del mismo era la ovista, que defendía que el homúnculo preformado se encontraba en el folículo ovárico. Para conocer las teorías embriológicas de la España Moderna véase Pelayo López, Francisco: "Las teorías de la Generación en España (16681767)" en Echeverría Ezponda, Javier; De Mora Charles, Marisol (Coord.). 1986 Actas del III Congreso de la Sociedad Española de Historia de las Ciencias : San Sebastián, 1 al 6 de octubre de 1984: vol. 1. 327-344. San Sebastián. 
deve dudarse si lo es, y diferir el Bautismo». ${ }^{33}$ Éste solo admitía una excepción a esta regla y era en el caso de que el feto corriera peligro. En esta situación, según él, el ser monstruoso debía ser bautizado sub conditione, debido a la escasa posibilidad que había de comprobar en un futuro si el ser era o no humano y poseedor, por tanto, de alma racional.

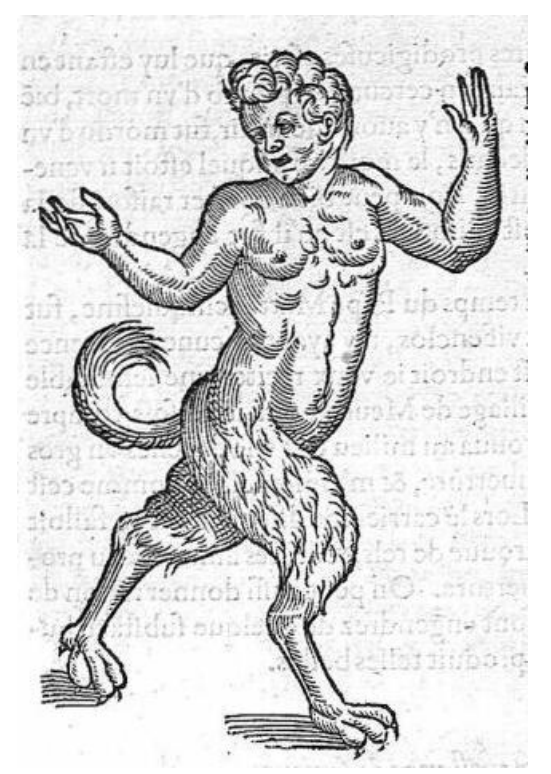

Ilustración 1- Monstruo híbrido mitad perro y mitad humano. Paré, Ambroise. 1558. Les Oueuvres de M. Ambroise Pare conseiller, et premier chirurgien du Roy...París: Chez Gabriuel Buon.

La segunda problemática en torno a la cuestión de las almas es la ya citada localización anatómica de las mismas en los monstruos bicípites o bicorpóreos (Ilustración 2). Para los clérigos de la Edad Moderna resultó indispensable saber en qué parte del cuerpo humano se encontraba, con el fin de saber si éstas estaban o no duplicadas, pues dos almas requerían dos bautismos. ${ }^{34}$ Para conocer la localización de las mismas era necesario saber qué órgano del cuerpo humano era el principal. En este sentido había dos opciones muy claras y diferenciadas: corazón o cabeza, que dividieron a los autores entre aquellos que defendieron la primera opción de aquéllos que sostuvieron la segunda, sin que se llegara a una conclusión fija. La teoría que consideraba al corazón como órgano principal y refugio del alma, partía de las ideas aristotélicas por el que aquél era la fuente de la vitalidad y, por tanto, donde no había más que un corazón no podía haber más que una vida y

33 Vicente Mas, Luis. 1770. Suma moral para examen de curas $y$ confesores: Parte I. Tratado III, cap. III, 93. Valencia: Por Francisco Burguete.

34 «era necesario el conocimiento de la localización anatómica del alma para poder deducir la administración del sacramento». Salamanca Ballesteros, Alberto. 2007: 221. 
una sola alma, aunque hubiesen dos cabezas. ${ }^{35} \mathrm{Y}$ al contrario, habían dos almas en los cuerpos en que hubiesen dos corazones y una sola cabeza. Muchos tratadistas de la época mostraron su inclinación hacia esta teoría, tal y como se observa en la obra del cirujano francés Ambroise Paré, al hablar sobre un niño bicípite nacido en París en el año 1546: "L'an 1546 à Paris une femme grosse de fix mois enfanta un enfant ayant deux testes, deux bras \& quatre iambes, lequel i'ouvry, \& n'y trouvay qu'un coeur: partant lon peut dire n'estre qu'un enfant». ${ }^{36}$ De la misma opinión se mostraba Pierre Boaistuau, manifestándose de la siguiente manera al referirse a un monstruo que nació en Cracovia: «... digo, que como el coraçon es la principal parte del animal, y que pues aquel no tenia mas de uno, es de cosa manifiesta, que tampoco no era mas de una sola criatura». ${ }^{37}$ Rivilla aunque reconocía la principalidad del corazón como órgano, descartaba, no obstante, que en él residiese el alma. $^{38}$

Más peso tuvo la teoría de la cabeza como órgano principal y refugio del alma. De origen platónico, fue defendida por la mayor parte de los médicos, cuyos fundamentos se basaban en que la cabeza era donde se ejercitaba las más nobles funciones como el entender, el discutir, el juzgar y el acordarse de las cosas. Autores como Pedro Mexía dedicaron capítulos a la «excelencia de la cabeça entre todos los miembros del hombre» en que afirmaba que «la cabeça, que es el más alto miembro de todos los del hombre, ventaja y preminencia es razón que tenga sobre todos los otros». ${ }^{39}$ También Antonio de Torquemada se mostró favorable al considerar la cabeza como refugio del alma:

«pario una muger dos mochachos, que del ombligo para abaxo era uno solo y del arriba eran dos diferentes, y tenían dos cabeças y dos pechos con todos los otros miembros, y se entendía claramente ser dos personas y dos animas distinas: porque llorava el uno y reya el otro, dormía el uno y velava el otro, y hazian otras diferentes operaciones». ${ }^{40}$

35 Cfr. Aristóteles. 1994. Reproducción de los animales, Madrid: ed. Gredos, Introducción, traducción y notas de Ester Sánchez. Lib. IV. 773a, p. 267.

${ }^{36}$ Paré, Ambroise. 1585. Les Oueuvres de M. Ambroise Pare conseiller, et premier chirurgien du Roy...: Cap. III. M. XXV. Paris: Chez Gabriel Buon.

37 Boaistuau, Pierre. 1603. Historias prodigiosas y maravillosas: 350 , Madrid: Por Luis Sánchez. Traducido al castellano por Andrea Pescioni.

${ }^{38}$ Rivilla Bonet y Pueyo, José. 1695, Cap. IX. Fol. 67.

39 Mexía, Pedro. 1989. Silva de Varia Lección: 333, Madrid: ed. Cátedra.

40 Torquemada, Antonio. 1575. Jardín de Flores curiosas: 44, Madrid: Imprenta de Iván Corderio. 
El caso expuesto por Antonio de Torquemada, sin embargo, no ayuda al lector a decidir sobre cuál era el refugio del alma, ya que habla de un tipo de monstruo bicípite en que tanto la cabeza como el pecho estaban duplicados, por lo que era fácil concluir que el alma también lo estaba. Pero ¿Qué ocurría cuando el cuerpo se encontraba duplicado y había una sola cabeza? ¿Poseía un alma o dos? Siguiendo la teoría de la cabeza como órgano principal se debe concluir que, en caso de que se diese este fenómeno, el ser poseía una sola alma al haber una única cabeza. No obstante, Nieremberg, partidario de la primacía de la cabeza, ${ }^{41}$ explicaba que en tales casos no podía decirse que el individuo poseyese una única alma por poseer una única cabeza, pues aunque el bulto de la cabeza fuese uno, la sustancia podía ser dos y, por tanto, poseer dos cerebros y dos almas. ${ }^{42}$

Tanto el caso de Torquemada como el de Nieremberg dejan en evidencia algo: que no era el número de cabezas el que indicaba el número de almas sino la racionalidad de éstas. Es decir, el comportamiento del ser bicípite y/o bicorpóreo revelaba de manera clara si el ser monstruoso poseía el alma duplicada, pues era la esencia y no la apariencia la que predominaba a la hora de clasificar al monstruo bicípite como un individuo o dos. Esta teoría la explicaba de manera muy clara Nieremberg en el Libro III, capítulo XXII donde enumeraba una serie de reglas que permitían saber la cantidad de almas del ser monstruoso:

"Y assi llegando ya a dar las reglas digo, que quando ay contrariedad en las acciones corporales, ò ímpetus diversos, que es señal de que son dos sujetos [...] la segunda regla sea por el imperio en las acciones, si queriendo el uno hazer algo le obedecen los miembros del uno, y otro cuerpo. Esto será señal de que el alma es una, pues su jurisdicción alcança a todo el monstro. La tercera, sea por los sentidos, si herida ò tocada qualquier parte del cuerpo lo siente, y gime qualquier cabeça. Mas si la una no llora, ni lo siente serán diversos los supuestos...». ${ }^{43}$

41 «y no está la silla y corte principal del alma en el coraçon sino en el cerebro». Nieremberg, J. Eusebio. 1649. Curiosa y oculta filosofía: Lib. III. Cap. XIV, 74, Alcalá: Imprenta de María Fernández.

42 «Sospecho que aun no es constante argumento la unidad de las cabeças para la singularidad del sujeto, si el resto del cuerpo es doblado. Lo primero, porque el bulto de la cabeça puede mentir una, y ser en esencia dos, por tener dos celebros informado cada uno con diversa anima» Ibidem Lib III. Cap. XX, 78.

${ }^{43}$ Ibidem: Lib. III. Cap. XXII, 79-81. 
Este autor hablaba ciertamente desde el conocimiento, pues él mismo había tenido la oportunidad de examinar a un monstruo bicípite que había visitado la corte madrileña en $1629 .{ }^{44}$ Se trataba de los famosos hermanos italianos Lázaro y Juan Bautista Coloreto. ${ }^{45}$ El jesuita quedó muy impresionado por la presencia de éstos, a los que describió como una simbiosis admirable, donde todo estaba afinadamente calculado para que los sistemas funcionaran al unísono. Concluyó, además, que ambos poseían almas diferentes y que eran dos personas distintas, a pesar de que Juan Bautista dependiera en todo de su hermano Lázaro.

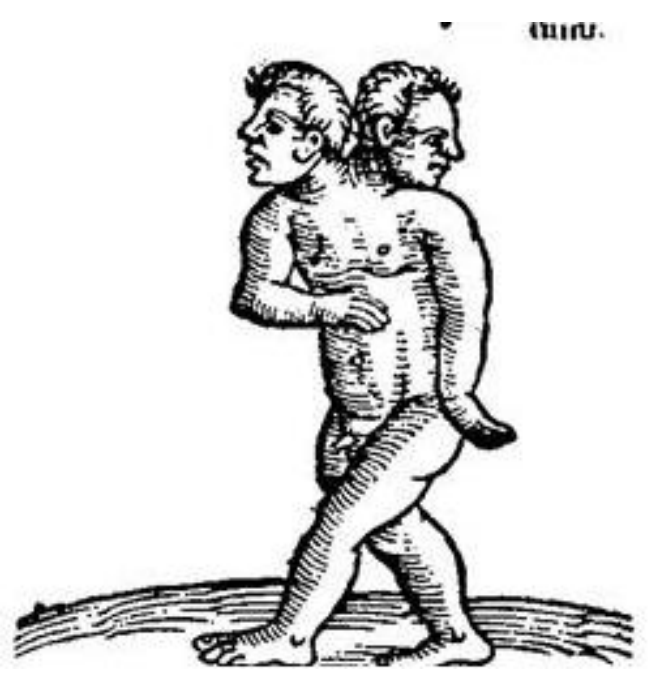

Ilustración 2- Monstruo bicípite. Lycósthenes, Conrad. 1557.

Prodigium ac ostentorum chronicon, Basilea: Per Hernl.

El debate sobre cabeza versus corazón perduró hasta bien entrado el siglo XVIII, como se observa en la carta sexta del tomo primero de Cartas eruditas y curiosas del padre Feijoo. En ella, se recogía el famoso caso del nacimiento del monstruo de Medina Sidonia quien ante el peligro de muerte fue bautizado de urgencia. El bautismo, practicado sobre un pie, fue declarado dudoso y ante ello se recurrió a la erudición del autor para que resolviese si la criatura había sido bautizada o no. Con todo, antes de entrar en cuestión, Feijoo reflexionaba sobre la cantidad de almas que poseían dichos seres sacando a relucir el debate ya existente:

«sólo he visto constituida la duda sobre la preferencia entre el corazón, y la cabeza; pretendiendo unos, que se ha de decidir la unidad, o duplicidad de almas precisamente por la unidad, o duplicidad del corazón: otros al contrario, por la de la cabeza, por consiguiente todos suponen, que estando acordes cabeza, y

44 Ibidem: Lib. III. Cap. I, 63-64.

${ }^{45}$ Cfr. Bondeson, Jan (ed.). 2000. The Two-Headed Boy, and Other Medical Marvels. USA: Cornell University Press. 
corazón, en cuanto al número, no hay lugar a cuestión; dando unos, y otros por cierto, que si no hubiere más que una cabeza, y un corazón, no hay más que un alma; y si hay dos cabezas, y dos corazones, son también dos las almas [...]. Si no tenía cada uno de aquéllos dos corazones [hace referencia al monstruo de Medina Sidonia, que al poseer dos corazones y dos cabezas la duda sobre la duplicidad del alma ya se hallaba resuelta], se sigue, que basta la duplicación de cabezas para inferir duplicidad de almas»». ${ }^{46}$

Es necesario puntualizar que Feijoo, en este caso, no hacía referencia a la racionalidad sino a la cabeza en sí, por lo cual queda la duda sobre si basaba sus argumentaciones únicamente en la cantidad de las mismas o en la presencia de varias racionalidades.

Menos seguro en este sentido se mostraba el jesuita Lorenzo de Hervás y Panduro, quien con estas palabras negó el hecho de que se supiese cuál era el órgano principal del ser humano: «Mas nuestra Física [...] Ignora también, qual es el punto verdaderamente central de las operaciones vitales; y quizá no llegará a descubrir fácilmente el verdadero sitio en que se aloja el alma que vivifica todo el cuerpo». ${ }^{47} \mathrm{La}$ única manera de saber cuáles eran los órganos necesarios para la vida, según este autor, era mediante la observación. A través de ella, el jesuita llegó a la conclusión de que un hombre no podía vivir sin cabeza pero que sí podía vivir algún tiempo -muy breve - sin corazón, lo que probaba que era aquélla el refugio del alma:

«En esta suposición se puede afirmar absolutamente, que los hombres mueren luego que les falta la cabeza; y que nos consta, que no mueren inmediatamente cortando, faltando o corrompiendoseles qualquiera de los otros miembros. Según esto, tenemos fundamento cierto para establecer, que el alma no abandona el cuerpo humano faltándole qualquiera miembro, que no sea la cabeza». ${ }^{48}$

\section{EL SACRAMENTO DEL BAUTISMO}

Tal y como explicábamos al principio de este trabajo, la Iglesia mostró interés en admitir al ser deforme como parte integrante de la misma a través del sacramento del bautismo. Sin embargo, la cantidad de matices y protocolos que formaba parte del ritual, tales como sus

${ }^{46}$ Feijoo, Benito. 1777. Cartas eruditas y curiosas, Madrid: Imprenta Real de la Gaceta. Tomo primero, carta sexta, "Respuesta a la consulta..." (1742).

${ }^{47}$ Hervás y Panduro, Lorenzo. 1784. Historia de la vida del hombre: 180 , Madrid: Imprenta de Aznar.

48 Ibidem: 181-182. 
fórmulas, ${ }^{49}$ dificultaban significativamente la tarea y la cuestión de las almas indicaba qué monstruos debían ser bautizados y cuáles no, como bien señala Elena del Rio Parra:

«La Iglesia tiene previsto cómo debe administrarse el sacramento a un ser que está naciendo, pero el ser deforme pone en tensión la prolijidad de las categorizaciones eclesiásticas, y acentúa la exclusión de lo diferente; desde sus propios términos, impone incluso a la religión la necesidad de reconocer su humanidad». ${ }^{50}$

Toda esta cantidad de matices obligaron a que en los manuales de confesores se dedicase un apartado especial al bautismo de los monstruos, que explicase de manera clara qué tipos eran "aptos" para el bautismo y cómo debían ser bautizados. Es en la Edad Media cuando ya encontramos las primeras instrucciones detalladas sobre ello. Para John Friedman, el primer manual de párroco que incluía estas instrucciones es el Manipulus curatorum de Guido del Monte Rocher (Ilustración 3), el cual tuvo más de cien ediciones hasta finales del siglo XVI. Este autor fue un cura español -llegó a ser obispo de Valencia en el siglo XIV- y estaba bien versado en las leyes canónicas y en la teología eclesiástica. En su obra proveía una serie de guías a los párrocos con bastante contingencia, simplificando los problemas y expresando la importancia del alma sobre el cuerpo, dejando entrever que en los monstruos con dos cuerpos habría probablemente dos almas. ${ }^{51}$

49 Lucía Orsanic explica de manera detallada las distintas fórmulas usadas. Orsanic, Lucía. 2012. "Si es homo...sobre el problema del bautismo de monstruos en los manuales para párrocos y los tratados de embriología sagrada", recurso en línea: http://www.academia.edu/1755103/ Si es homo... Sobre el problema del b autismo de monstruos en los Manuales para Parrocos y los Tratados de Embriologia Sagrada [Consultado 12-Diciembre-2012]

${ }^{50}$ Del Rio Parra, Elena. 2003: 105.

${ }^{51}$ Friedman, John Block. 1981: 182. 


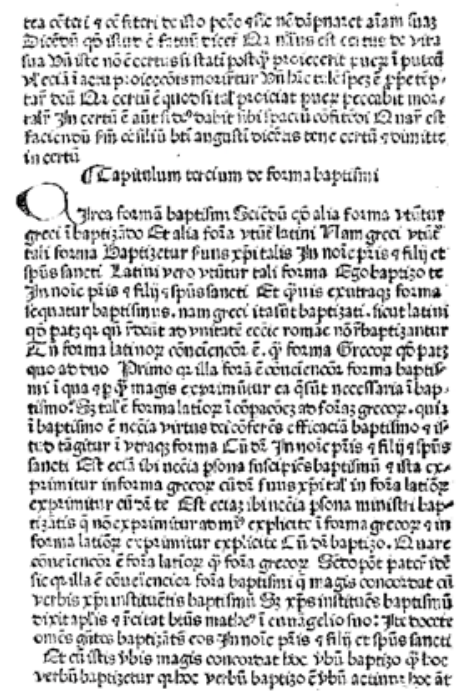

Ilustración 3- Extracto de Manipulus Curatorum de Guido de Monte Rocher.

Muchos de estos manuales, como bien señala Luisa Ruiz Moreno, se hallaban en hospitales y tenían como objetivo principal el socorrer a los párrocos en caso de que surgiesen problemas, los cuales estaban vinculados -en su mayoría- a la propia ideología de la institución eclesiástica más que en los propios feligreses. ${ }^{52} \mathrm{Y}$ no sólo los párrocos, sino que también comadronas -quienes igualmente podían administrar el bautismo en caso de urgencia- disponían de ellos para saber hasta qué punto debían o no bautizar a los niños monstruosos. ${ }^{53}$

Junto con los párrocos y los eclesiásticos, los tratadistas teratológicos de la Edad Moderna también mostraron preocupación en sus escritos. Eusebio Nieremberg, por ejemplo, se expresaba de la siguiente manera:

«Acerca del bautismo de los monstruos dudosos, se ha de advertir mucho donde se les echa el agua a los que salen con formas muy agenas, y artificiales, si se resolviere que tienen probablemente el alma humana, digo esto, porque puede ser que aquellas figuras exteriores no sean parte del monstro, sino como covertura, y túnica descontinuada con que estè embuelto». ${ }^{54}$ 22: 46 .

${ }^{52}$ Ruiz Moreno, Luisa: “¿Cómo bautizar a los monstruos?”, Elementos

53 Salamanca Ballesteros, Alberto. 2007: 90. Salamanca Ballesteros además explica que en caso de que el feto no fuera "apto" para bautismo estaba permitido legalmente matarlos.

${ }^{54}$ Nieremberg, J. Eusebio. 1649: Lib. III. Cap. XXVIII, 86. 
Asimismo, José Rivilla dedicó todo un capítulo de su obra al bautismo, centrándose en el monstruo bicípite que había nacido en Lima en el año 1694. Este tipo de seres, tal y como hemos visto en el apartado de las almas, fue el que más problemas generó, no sólo en el aspecto religioso sino también en el legal, de ahí que fuese prioridad absoluta saber no sólo si la criatura debía ser bautizada o no, sino también cuántas veces. En este sentido, el mencionado autor explicaba que en los casos de monstruos bicorpóreos en los que hubiesen dos cabezas bien formadas - es decir, sin ningún tipo de deficiencia mental-, se debía proceder bautizando a ambas por igual en los casos de urgencia, pero en los casos de bautismo puro ambas debían dar algún tipo de señal que demostrase que en realidad las dos poseían racionalidad. En el caso de que una de ellas poseyera algún tipo de imperfección, ésta no debía ser bautizada, administrándose el bautismo únicamente en aquellas cabezas consideradas perfectas. ${ }^{55}$ Asimismo, Francisco Larraga explicaba lo siguiente: «Pero si el monstruo tiene el cuerpo duplicado, de manera que se duda si es uno, ó es dos hombres, se les debe administrar dos veces el Bautismo; una absoluta en la parte mas perfecta, y otra condicionalmente en aquella parte, que muestra mas imperfección de miembros». ${ }^{56}$ Esta resolución también fue sostenida por algunos socios de la Regia Sociedad de Medicina y otras Ciencias de Sevilla, tales como Martín Guzmán en cuya opinión debían ser bautizadas de manera absoluta ambas cabezas si éstas demostraban ser independientes mediante acciones opuestas; pero en caso de subordinación, debía ser bautizada de manera absoluta aquélla que mostrase una mayor independencia, administrándose el bautismo sub conditione sobre la otra. ${ }^{57}$

En los casos de monstruos bicípites distintos en lo superior pero mezclados en lo inferior con sólo dos piernas, según Rivilla, cualquier pie que se bautizase durante el bautismo de urgencia implicaba que ambos cuerpos quedaban perfectamente bautizados. ${ }^{58}$ Sin embargo, no era de la misma opinión Feijoo que al tratar el caso del monstruo de Medina Sidonia, sobre el cual se había ejercido un bautismo de urgencia en el pie, explicaba que éste no había quedado debidamente bautizado. En primer lugar, porque al ser individuos distintos la moral exigía un doble bautismo y, debido al peligro de muerte y al ignorar que eran dos, sólo se le había practicado uno y bajo la fórmula ego baptizo; y en segundo lugar, porque dicha fórmula únicamente se usaba cuando el párroco sabía sobre quién lo administraba, en este caso, al ser dos individuos, el

${ }^{55}$ Rivilla Bonet y Pueyo José. 1695: Cap. X, 79.

56 Larraga, Francisco. 1819. Promptuario de la Theología moral: 25, Pamplona: Por la viuda de Rada.

57 Hermosilla Molina, Antonio. 1970: 564.

58 Ibidem: 79. 
párroco ignoraba sobre quién estaba administrando el bautismo -lo había hecho sobre un pie y era imposible identificar a quien pertenecía- por lo que la fórmula era incorrecta, invalidando de este modo el mencionado sacramento. Feijoo concluía, por tanto, que el monstruo de Medina Sidonia no había sido correctamente bautizado.

Con este caso y la correspondiente explicación de Feijoo se aprecia, que el bautismo estaba conformado por una serie de rituales y fórmulas que podían determinar el valor del mismo. Para los monstruos bicípites, lo más correcto era derramar el agua bendita sobre ambas cabezas, si estaban debidamente conformadas -es decir, sin ningún tipo de deficiencia que los privara de racionalidad-, y una vez que se hubiesen identificado como dobles individuos y poseedores de almas duplicadas, es decir, que el monstruo bicípite diera muestra, tal y como explicaba Nieremberg, que estaba conformado por dos individuos completamente diferentes con sentimientos y acciones propias. El bautismo, para ser correcto, debía ser doble como así lo señalaba Vicente Mas: "Pero si contare, que son dos hombres, por tener dos cabezas enteras y perfectas, con division de pechos, y movimientos opuestos; deven separada y absolutamente bautizarse ambas cabezas». ${ }^{59}$

Y al igual que con la cuestión de las almas, no sólo los monstruos bicorpóreos y/o bicípites generaron problemas. Los producidos por la conmixitión de especies también constituyeron un verdadero quebradero de cabeza para párrocos y tratadistas. Uno de los más duros al tratar este tema fue José Rivilla, quien ya vimos que negó toda posibilidad de que estos seres poseyeran alma racional, por lo que no resulta raro que también les negase el bautismo: «Los monstruos nacidos de conmixtion de especies, parte de la humana, y parte de la de varios animales, no son capaces de Baptismo. Fundase en la incapacidad que tienen del alma racional de qualquier suerte que nacen aunque sea con la cabeça humana». ${ }^{60}$ Sin embargo, éste admitía un bautismo condicional en los monstruos nacidos de madres brutas -animal- pero enteramente humanos, pero sólo en caso de necesidad. ${ }^{61}$ Una vez que la criatura estuviese fuera de peligro y su vida totalmente asegurada, debía esperarse determinadas señales que garantizasen la humanidad de la

${ }^{59}$ Vicente Mas, Luis. 1770: Cap. III, 93.

${ }^{60}$ Rivilla Bonet y Pueyo, José. 1695: Cap. X, 75.

61 El ya mencionado Larraga explicaba que en caso de que el niño naciese únicamente con cabeza de animal se debía esperar a que se confirmara que poseía razón, a menos que la criatura corriera peligro de muerte, en tal caso debía ser bautizado condicionalmente. Larraga, Francisco. 1819: 25. 
misma para poder administrarle el bautismo puro ya que, tal y como explicaba dicho autor,

«pueden ser verdaderos partos de la bestia (que suele suceder como se à dicho) y entonces es lo cierto, no poder ser humanos, ò ya ser supuestos por el Demonio siendo verdaderamente humanos hijos de padres racionales lo qual puede acontecer de los modos que quedan asignados en dicho capitulo 5 num. $38 » .{ }^{62}$

Asimismo, los monstruos nacidos de padres racionales con cabeza humana aunque con algunos miembros de animal, también debían ser bautizados pues, según el principio teológico, todo humano de la estirpe de Adán era capaz de bautismo. Consecuentemente, todas las naciones monstruosas como los Sciopodas, pigmeos, cinocéfalos, etc. que también fueron consideradas descendientes de Adán $\mathrm{y}$, por tanto del género humano, eran capaces de bautismo. ${ }^{63}$

En la segunda mitad del siglo XVIII nos seguimos encontrando con instrucciones parecidas a las que daban los manuales de confesores 0 las ofrecidas por Rivilla. En 1763, por ejemplo, hallamos la obra de Antonio José Rodríguez: Nuevo aspecto de teología médico-moral. En ella dedicaba la Paradoja $\mathrm{V}$ al debate sobre si debía ser bautizado sub conditione el monstruo nacido de madre humana y engendrado por bruto, para lo cual explicaba que lo largo de los siglos la teología moral había mantenido la creencia de que sólo debían ser bautizados bajo condición lo monstruos nacidos de madre animal y padre humano, rechazándoselo a aquél que hubiera nacido de madre humana y padre animal. ${ }^{64}$ Los motivos de esta permisión para unos y no para otros, aunque en esencia fueran lo mismo, eran dos: "La primera es, que es mas constantemente admitido en la Physica, que el concurso activo, y aun material le presenta

62 Ibidem: 77.

63 John Friedman explica que en el siglo VI las razas monstruosas fueron consideradas cristianos potenciales, ya que San Agustín decía que si eran descendientes de Adán tenían almas, y que si tenían almas entonces podían ser salvados. Por tanto, las razas monstruosas figuraron en un programa de salvación de la Iglesia. Las actividades misioneras entre las razas monstruosas se convirtieron en un tema popular entre los cristianos evangelistas quienes daban la bienvenida a la ocasión de cumplir con la obligación que Cristo había asignado a los apóstoles antes de su ascensión. Friedman, John. 1981: 59.

64 «La teología moral decreta que se baptizen baxo de condición los monstruos nacidos de una madre bruta y masculo racional, pero que no se bapticen, los que nacen de hembra racional, y padre bruto». Rodríguez, Antonio Joseph. 1763. Nuevo aspecto de theología médico-moral, y ambos derechos, o paradoxas physico-theologico legales: 48, Madrid: Imprenta real de la Gaceta. 
el masculo, que la hembra se ha [sic] mere passive. La segunda, que para la generación de hombre, es indispensable la simiente de hombre». ${ }^{65}$ Estas pocas líneas demuestra lo que ya habíamos explicado con anterioridad: el peso de las ideas aristotélica en la teoría de la reproducción humana. Sin embargo, a pesar de lo que pudiera parecer en un principio, José Antonio Rodríguez rechaza la concepción aristotélica de la generación del hombre mostrándose como un ferviente defensor del preformacionismo en su vertiente ovista, ${ }^{66}$ por lo que en su opinión, en caso de madre humana y el padre bruto el bautismo debía ser absoluto:

«si la deformidad del feto en question es solamente en alguna mano, ò pie, ù oreja, ò en fin que sea poco el receso de la figura humana, me parece que el Baptismo deberá ser sin condición alguna, sino absoluto. [...] Y solamente deberá ser baxo de condición, quando la monstruosidad sea muy sensible». ${ }^{67}$

Pero en el caso contrario -padre humano y madre bruta-, el bautismo sí debía ser condicionado pues el autor dudaba si dicha criatura poseía alma racional: «si sucediese (que constantemente dudo que suceda) el que de la mixtión de masculo hombre, y hembra bruta saliese feto, que toda su figura, [...] sea humana, deberá baptizarse baxo de condición; porque aun en ese caso dudaré de que le anime alma racional». ${ }^{68}$

La Paradoja VI la dedicaba igualmente al bautismo, en este caso sobre si se debía bautizar de manera condicional a los monstruos nacidos de mujer aunque careciesen totalmente de figura humana. Para lo cual explicaba que, a pesar de la apariencia del monstruo, no debía dudarse de su racionalidad pues había multitud de causas por las que una criatura podía salir deforme y, por tanto, totalmente diferente a la madre. Es por eso que no se debía dudar en bautizársele aunque fuera de manera condicional: "quando razonablemente hay duda de que informa Alma de hombre al monstruo, debe baptizarse bajo de condición; sed sic est, que en monstruos nacidos de muger, aunque tengan la

65 Ibidem

66 El padre Antonio José Rodríguez se manifiesta claramente ovista tanto en Palestra crítico-médica (1731-1739) como Carta-respuesta a un ilustre prelado sobre el feto monstruoso hallado poco hà en el vientre de una cabra... (1753) donde hacía una férrea defensa de esta postura frente a las dudas que había mostrado Benito Feijoo en la carta XXX de Cartas eruditas y curiosas (1750) a raíz del hallazgo de un feto humano en el vientre de una cabra.

67 Rodríguez, Antonio Joseph. 1763: 52-53.

${ }^{68}$ Idem 
exterior figura totalmente extraña, hay esta razonable duda: luego deben baptizarse baxo de condición». ${ }^{69}$

Ya a finales del siglo XVIII nos encontramos con dos obras, por un lado la ya mencionada de Hervás y Panduro quien afirmaba con respecto al bautismo de los monstruos híbridos:

"y siempre se deban bautizar los fetos humanos por mas parecidos que sean a las bestias», ya que para él "La certidumbre de ser humano el feto que nace de mujer, y la experiencia de verle viviente, son dos pruebas prácticas que nos obligan a reconocerle animado de espíritu inmortal o humano. La vida es efecto indubitable de la existencia y animación del espíritu; y la inmortalidad es esencial y característica de todo espíritu que anima qualquier feto humano, por mas monstruoso que sea en su figura y organización». ${ }^{70}$

Este mismo autor trató, además, la cuestión del bautismo de los hermafroditas ${ }^{71}$ ante la problemática -que él mismo explicaba- de que si a un ser se le bautizase como niño y luego resultara ser niña, el bautismo quedaría del todo invalidado. El autor, que se muestra totalmente reticente a esta idea, respondía de la siguiente manera: «El bautismo se da á una persona humana; y no es cosa substancial para su virtud, la distinción del sexo. Si en algún infante no se distingue el sexo, se deba bautizar suponiéndole de un sexo determinado; y el Bautismo será válido...». ${ }^{72}$

La segunda obra es la de Francisco Cangiamila, Embriología sagrada (1785), cuyo capítulo VIII del libro II está dedicado enteramente al bautizo de los monstruos en el que explicaba una serie de instrucciones como las siguientes:

"Quando el monstruo tiene cabeza humana, y se ve en su exterior, figura y conformación de hombre, se le bautizará á lo menos baxo esta condición: Si es homo, vc. Si eres hombre, yo te bautizo. Si el monstruo tiene solamente cabeza humana, y lo demás miembros son de irracional, lo que ha sucedido

${ }^{69}$ Ibidem: 61.

${ }^{70}$ Hervás y Panduro, Lorenzo. 1784: 171-172.

${ }^{71}$ Uno de los mejores trabajos sobre los hermafroditas es el siguiente: Cleminson, Richard; Vázquez García, Francisco. 2009. Hermaphroditism, Medical science and Sexual Identity in Spain, 1850-1960, Cardiff: University of Wales Press.

${ }^{72}$ Hervás y Panduro, Lorenzo.1784: 189. 
varias veces, es probable que tiene alma racional: sin embargo, no se le debe bautizar sino baxo de condición...». ${ }^{73}$

\section{CONCLUSIÓN}

El bautismo, como primer sacramento de la Iglesia Católica y puerta de los otros, debía ser administrado de forma cuidadosa sabiendo quiénes eran "aptos" para recibirlo y cómo debían recibirlo. El nacimiento de seres monstruosos, que suponía incógnitas en diversos campos ¿por qué nacían? ¿Qué causas lo generaban? ¿Cómo debían tratarse?-, generó diferentes problemas a la hora de administrar este sacramento. Los clérigos, tratadistas, e incluso, médicos dedicaron numerosas páginas a reflexionar sobre las almas y sobre los rituales y fórmulas que debían seguirse. Sus escritos tenían un fin particular: ayudar a los párrocos y, también a comadronas, que se veían obligados a bautizarlos, ya que bajo la premisa de la perfección del alma inmortal todos los seres, por muy monstruosos que fuesen, eran admitidos en la fe verdadera contenida en la religión católica.

La cuestión de las almas fue una de las principales discusiones que se generó en torno al bautismo. Ésta era un elemento esencial y su racionalidad era el requisito principal para ser apto. Saber si el monstruo o no disfrutaba de alma racional produjo un debate en el que se incluyó todo tipo de seres, desde aquellos que poseían una mera imperfección hasta los que habían sido fruto de la conmixtión de especies. Los clérigos y tratadistas se esforzaron al máximo a la hora de calificar estos seres, y de conocer hasta qué punto sus almas gozaban de la racionalidad necesaria para el acceso al mencionado sacramento. $Y$ si conocer la racionalidad de las almas fue fundamental, no menos importante fue conocer su localización -marcado por el debate cabeza versus corazón-, especialmente en los casos de seres siameses cuya dificultad residía en saber si eran un individuo o dos.

Junto la problemática de las almas, nos encontramos la del funcionamiento del ritual. Las fórmulas necesarias para proceder con el sacramento del bautismo eran de absoluta importancia, ya que éstas podían hacer que un bautizo fuese totalmente invalidado. Para los seres monstruosos había toda una serie de rituales y fórmulas que garantizaban su bautizo y su salvación en el más allá. Muchas de éstas eran incondicionales pero otras eran sub conditione pues no

73 Cangiamila, Francisco. 1785. Embriología sagrada o tratado de la obligación que tienen los Curas...: 189. Madrid: Imprenta Pantaleon Aznar. Traducido al castellano por el doctor Don Joaquín Castellot. 
queriéndoles negar el primer sacramento de la Iglesia católica tampoco se les quería otorgar a seres cuya naturaleza era cuanto menos dudosa.

El bautismo, por tanto, aunque se ofrecía como un sacramento de fácil acceso para todo ser, se convertía en un ritual complicado en el que había que cumplir con una serie de condiciones, y que se debía de administrar bajo una serie de fórmulas y rituales diferentes en función del tipo de ser que fuera acceder a él.

\section{FUENTES IMPRESAS}

Aldrovandi, Ulises. 1642. Monstrorum historia, Bolonia: Hieronimus Tamburinus.

Boaistuau, Pierre. 1603. Historias prodigiosas y maravillosas, Madrid: Por Luis Sánchez. Traducido al castellano por Andrea Pescioni.

Cangiamila, Francisco. 1785. Embriología sagrada o tratado de la obligación que tienen los Curas... Madrid: Imprenta Pantaleon Aznar. Traducido al castellano por el doctor Don Joaquín Castellot.

Cliquet, José Faustino. 1781. La flor del mora o recopilación legal, firme, y opulenta, de lo mas florido, y selecto... Madrid: Por Antonio Sanz.

Corella, Jaime. 1702. Suma de la theologia moral, Barcelona: Imprenta de de Joseph Llopis,

Covarrubias, Sebastián de. 1977. Tesoro de la lengua castellana, Madrid: ed. Turner.

Feijoo, Benito. 1777. Cartas eruditas y curiosas, Madrid: Imprenta Real de la Gaceta.

Fuentelapeña, Fray Antonio de. 1677. El ente dilucidado. Discurso único novísimo que muestra hay en naturaleza animales irracionales invisibles y quales sean, Madrid: Imprenta real.

García Carrero, Pedro. 1605. Disputationes medicae, Madrid: ex Officina lusti Sanchez Crespo.

Hervás y Panduro, Lorenzo de. 1789. Historia de la vida del hombre, Madrid: Imprenta de Aznar. 
Larraga, Francisco. 1819. Promptuario de la Theología moral, Pamplona: Por la viuda de Rada.

Mercado, Luis. 1594. De Mulierum affectionibus, Libri quatuor, Madrid: Apud Thomam luntam

Mexia, Pedro. 1989. Silva de Varia Lección, Madrid: ed. Cátedra.

Nieremberg, Juan Eusebio. 1649. Curiosa y oculta filosofía, Alcalá: Imprenta de María Fernández.

Paré, Ambroise. 1585. Les Oueuvres de M. Ambroise Pare conseiller, et premier chirurgien du Roy...Paris: Chez Gabriel Buon.

Rivilla Bonet y Pueyo, José 1695. Desvíos de la naturaleza o tratado del origen de los monstruos, Lima: Imprenta Real.

Rodríguez, Antonio José. 1763. Nuevo aspecto de theología médico-moral, y ambos derechos, o paradoxas physico-theologico legales. Madrid: Imprenta real de la Gaceta.

Torquemada, Antonio de. 1575. Jardín de Flores curiosas, Madrid: Imprenta de Iván Corderio.

Vicente Mas, Luis. 1770. Suma moral para examen de curas y confesores, Valencia: Por Francisco Burguete.

Von Plenk, Josep Jacob. 1796. Medicina y cirugía forense ó legal, Madrid: Imprenta de la viuda e hijo de Marín, 1796. Traducida al castellano por Higinio Antonio Lorente.

\section{BIBLIOGRAFÍA ACTUAL}

Ashworth Jr., William B: "Natural history and the emblematic world view" en Lindberg, David C. y Westman, Robert S. (Eds.) 1990. Reappraisals of the scientific revolution: 303-332. Cambridge: Cambridge University Press.

Canellas Anoz, Magdalena (Coord.). 2010. Sucesos curiosos II en la Andalucía del Antiguo Régimen, Sevilla, Ed. Junta de Andalucía.

Del Río Parra, Elena. 2003. Una era de monstruos: representaciones de lo deforme en el Siglo de Oro español, Madrid: ed. Iberoamericana. 
Flores de la Flor, Ma Alejandra. 2011. "Los monstruos híbridos en la Edad Moderna", en Morgado García, Arturo; Rodríguez Moreno, José Joaquín (Coord.): Los animales en la historia y en la cultura: 143-152. Cádiz: Servicio de Publicaciones de la Universidad de Cádiz.

Friedman, John Block. 1981. The monstrous races in medieval art and thought, Cambridge (Massachusetts): Harvard University Press.

Hermosilla Molina, Antonio. 1970. Cien años de medicina sevillana, Sevilla, Diputación provincial.

Lafuente, Antonio; Valverde, Nuria. 2000. "¿Qué se puede hacer con los monstruos?" en VV. AA.: Monstruos y seres imaginarios en la Biblioteca Nacional:15-38. Madrid: Algete.

Martínez Gil, Fernando. 2000. Muerte y sociedad en la España de los Austrias, Cuenca: Servicio de Publicaciones de la Universidad de Castilla-La Mancha.

Morgado García, Arturo: "Discursos eclesiásticos en la España de Felipe V", en Pereira Iglesias, J. L. (Ed.). 2002. Felipe V de Borbón 17011746: actas del Congreso de San Fernando (Cádiz) de 27 de noviembre a 1 de diciembre de 2000: 435-466. Córdoba: Ed. Universidad de Córdoba y Fundación Municipal de San Fernando.

Orsanic, Lucía. 2012. "Si es homo...sobre el problema del bautismo de monstruos en los manuales parapárrocos y los tratados de embriología sagrada", recurso en línea: http://www.academia.edu/1755103/ Si es homo... Sobre el problema del bautismo de monstruos en los Manuales para Parrocos y los T ratados de Embriologia Sagrada [Consultado 12-Diciembre-2012].

Pelayo López, Francisco: "Las teorías de la Generación en España (1668- 1767)" en Echeverría Ezponda, Javier; De Mora Charles, Marisol (Coord.). 1986 Actas del III Congreso de la Sociedad Española de Historia de las Ciencias : San Sebastián, 1 al 6 de octubre de 1984: 327344. San Sebastián.

Ruiz Moreno, Luisa: “¿Cómo bautizar a los monstruos?", Elementos 22: 45-49.

Salamanca Ballesteros, Alberto. 2007. Monstruos, ostentos y hermafroditas, Granada: ed. Universidad de Granada.

Wilson, Dudley. 1993. Signs and portents. Monstruous birth from the Middle Ages to the Englightenment, Londres/Nueva York: Routedge 